\title{
THE COMPARISON RESEARCH ON THE OFFICIAL WEBSITES INTERFACES OF THE CONFUCIUS INSTITUTE AND THE "RUSSKIY MIR" FOUNDATION
}

\author{
Margarita Gudova ${ }^{1 *}$ and $\mathrm{Si} \mathrm{XU}^{2}$ \\ ${ }^{1}$ Prof. Dr., Ural Federal University, Russia, MargGoodova@gmail.com \\ ${ }^{2}$ Postgraduate student., Ural Federal University, Russia, 809521688@qq.com \\ ${ }^{*}$ Corresponding author
}

\begin{abstract}
This article makes a comparative analysis of the official websites of the Confucius institute and "Russian World" foundation. The official websites recognize by the authors as an important part of cultural policy in the sphere of language's promotion and languages education. Based on theories of website evaluation and multimodal discourse analysis theory (G. Kress), the authors establish a system of evaluation indicators for the cases of the official websites to grasp the overall situation and problems of the current website construction more accurately.

Firstly, compared to "Russkiy Mir" Foundation, the official website of Confucius Institute is relatively better in construction and operation, but weak in design and overall style, the characteristic and cultural function performance does not very prominent either. Also, it lacks color modalities, image modalities, and video modalities and has no visual impact, making it difficult to establish an intimacy with visitors. Secondly, the "Russkiy Mir" Foundation's website is unique in content construction and design, but the operability and functionality are relatively weak. It leads to a poor internet experience for visitors.

In conclusion, the author proposes improvements to the two websites from the perspectives of strengthening the website settings and enriching the multimodal texts, hoping to help the two institutions to better promote language, culture, and cultural soft power.
\end{abstract}

Keywords: Confucius Institute, "Russkiy Mir"' Foundation, Website evaluation, Multimodal discourse analysis, G. Kress, Language education.

\section{INTRODUCTION}

\subsection{Background and Significance of the Study}

Over the past decade, the role of language export in building soft power has been recognized by countries around the world. The degree of internationalization of languages symbolizes the level of national soft power and has received a great deal of attention and appreciation from various countries. In every period of globalization, the principal hegemonic power has promoted its own language as a tool for unity across time and space. In nearly every case, economic, social, and/or political power tended to be tightly bound up in the reasons for widespread adoption of the flew medium of cross-cultural communication. 
Both China and Russia have incorporated the building of soft power into their national cultural strategies. "Raising the country's cultural soft power to a strategic position and stressing that to improve the country's cultural soft power, efforts should be made to consolidate the roots of the country's cultural soft power, efforts should be made to spread contemporary Chinese values, efforts should be made to demonstrate the unique charm of Chinese culture, and efforts should be made to improve the international discourse" [Xi Jinping, 2014, 201]. "The country's education and culture should be continuously made more involved in the world's educational and cultural development, and the dissemination of Russian educational and cultural ideas should be systematically increased in Russian-speaking or Russian-speaking countries". To give Russia a positive image in the international arena and allow the world to view Russia objectively, the Ministry of Foreign Affairs needs to further improve its foreign communications [V. V. Putin, 2012].

Therefore, in the context of different cultural and foreign policies, China and Russia have successively set up their own language and culture promotion institutions - the Confucius Institute and the "Russkiy Mir" Foundation. These institutions are more than just platforms for the promotion and teaching of languages, they are also staging for governments to uphold the national interests, enhance the national image and strengthen the international relations.

The Confucius Institute and the "Russkiy Mir" Foundation are respectively responsible for the promotion of language and culture. However, compared to the French Alliance Françoise, the British Council, and the German Goethe Institute, they are relatively new and still need to learn from their experiences to broaden their outreach channels and influence.

In addition, with the development of Internet technology, official websites have become an important channel for the promotion of language and culture. Kosachev [Kosachev, 2012] lists the Russian language promotion as an instrument of soft power to be developed and highlights the importance of the Internet in today's international community "The Internet is not only a new path to work but also a new object of behavior".

Apparently, compared with paper media, the official website which underlies a multimodal discourse communicates with readers by its use of verbal, visual language, video, hyperlinks are much more prevalent among the public with its timely and efficient merits. For language and culture promotion institutions, it makes information more accessible to visitors and creates a more vivid image. The design, operation, functionality, services, and content of an official website directly affect the experience of visitors and are, therefore, an effective indicator of an institution's work performance.

Therefore, it is essential to evaluate and analyze the interfaces official websites of cultural promotion institutions, but unfortunately, no researcher has conducted a comparative study of the Confucius Institute and the "Russkiy Mir" Foundation from this perspective.

In this paper, the author combines website evaluation theory and multimodal discourse analysis theory to establish a system of evaluation indicators for the Interfaces official websites of the Confucius Institute and the Russkiy Mir Foundation, to grasp the overall appearance and problems of the current website interfaces construction more accurately. Secondly, through a comparative analysis of the characteristics and current situation of the official websites of Confucius Institutes and "Russkiy Mir" Foundation interfaces, corresponding suggestions are made to provide references for future development.

\subsection{Literature Review}

\subsubsection{The research on the Comparison of Language Promotion Agencies Confucius Institute and the "Russkiy Mir" Foundation}

Li Qinzheng [Li Qinzheng, 2016] analyzes the geographical distribution, teaching activities, and cultural activities of Confucius Institute and the "Russkiy Mir" Foundation, finding the differences in mission, funding sources, composition form, and cultural, industrial relations. Similar studies have been done by Li Baogui [Li Baogui, 2017]. He studied the Confucius Institute in Russia and the Russian Language Centre in China from the perspective of cultural interaction and made a Summary of the consistency and differences between the philosophies of language and cultural communication institutions in Russia and China, focusing on four aspects: operation mechanism, management mode, teaching mode and cultural transmission mode, and then proposed development strategies for the Confucius Institute and the Russian Language Centre to achieve positive cultural interaction.

Chang Yishuo, Chen Mengjin, Cui Mingyue [Chang Yishuo, Chen Mengjin, Cui Mingyue, 2018] attempt to compare the Confucius Institute and the Russian Language Centre through the lens of intercultural communication, but unfortunately, their comparison remains in the clichéd perspective of the philosophy of 
schooling and funding. The subject of intercultural communication is only briefly outlined in terms of the communication channels of the two institutions, and the role played by the intercultural institutions, the conflicts encountered, and the communication strategies are not examined.

By comparing Confucius Institutes with Goethe-Institute, Dong Lu [Dong Lu, 2011] points out that the Confucius Institute should focus on spreading and teaching culture, rather than simply pursuing the construction of its branches and enrolling more students. In comparison, Liu Liping and Jiang Xinxin [Liu Liping and Jiang Xinxin, 2011] offer more insights into the sustainable development of Confucius Institutes, which relates to financial sustainability, theoretical support, qualitative teaching, and promoting activities. In addition to this, they also proposed strengthening interaction with overseas sinology institutions and the training of a new generation of sinologists.

However, most of the comparisons are basically on the organizational structure, language education, and culture promotion. Studies on the role of new communication channels like websites are not being addressed.

\subsubsection{Studies on Multimodal Discourse Analysis}

Kress \& Van Leeuwen [Kress \& Van Leeuwen, 1996] point out that multimodal refers to all channels and media, in addition to the basic linguistic symbols, it also includes resource symbol systems such as color, images, music, and color saturation. It means that multimodal discourse analysis is not just about the language itself, it is also about the interaction between language systems, semantic structures, psychocognitive, socio-cultural relations, as well as the representation of sounds, images, and actions [Gibbon D. Mertins I., Moore R., 2000]. It breaks with the single source of information in language analysis and incorporates multiple sensory systems [Zhang Delu, 2009], and should be set off with a dynamic view on semiotic [Ledema, 200].

Most researchers follow the social semiotic approach whose theoretical foundation lies in systemic functional linguistics. Roland Barthes [Roland Barthes, 1977], takes advertisement images as the analytical object, discusses the relationship between language and image in the meaning-making process. Based on Systemic-Functional Grammar, Kress, and van Leeuwen [Kress, and van Leeuwen, 1996] have made great achievements in building a theoretical framework for analyzing multimodal discourse. Another theoretical framework for multimodal discourse analysis is erected by Baldry and Thibault introduces the transcribing methods for analyzing multimodal discourse. As to multimodality on web pages, he defines three parameters of the interpersonal meaning potential.

Cheng, W., \& Suen, A. O. [Cheng, W., \& Suen, A. O. 2014] examines generic characteristics and visual images of Five Star hotel home pages in Hong Kong, using Bhatia's [Bhatia, 2004] multidimensional genre analysis and Kress and Van Leeuwen's framework. Distinguished from the former, Askehave \& Nielsen [Askehave \& Nielsen, 2005] propose new insights into the concept of genre, adapting traditional models of genre theory to web-mediated texts, which are related with a two-dimensional view on genres. In fact, website design is also influenced by cultural background after Chen Haiping [Chen Haiping, 2002] comparisons of webpages from Chinese universities and that of American.

\subsection{Theoretical basis and Theoretical framework}

\subsubsection{Value Evaluation Theory}

Value evaluation is one of the most important categories in the philosophy of value, and it has long been debated in academic and intellectual circles without reaching a consensus on the understanding of value evaluation. The evaluation is essentially a value-based study. It is inevitably rooted in the fertile ground of value evaluation theory. The philosophy of value originates from the distinction between facts and values. The distinction between 'facts' and 'values' was first made by the 18th century English philosopher Hume in his Treatise on Human Nature, and 'factual judgements' and 'value judgements' are incommensurable. Judgments of fact" and "judgments of value" are incommensurable. The absolute and relative nature of practice and the principle of absolute and relative truth lay the foundations of the value theory of evaluation. The importance of utility assessment in evaluation can be seen in Dewey's "Experience and Nature", which understands value in terms of practice, practical results and effectiveness, efficiency, effect, and performance. At the same time, the specialized and specific nature of website evaluation makes evaluation complex. In view of this, value systems theory plays an important theoretical role in the evaluation of websites. 


\subsubsection{Comparison and classification theory}

The cognitive subject's awareness of cognitive objects generally begins with the differentiation of objects, which is inseparable from comparison and classification. The evaluation itself is the process of comparing and classifying evaluation objects within an evaluation system, and the process of comparison is the process of evaluation, and the result of classification is the conclusion of the evaluation. Therefore, the theory of comparison and classification provides theoretical support for the evaluation of websites.

\subsubsection{The GeM (Genre and Multimodality) Framework}

The multimodal discourse analysis on webpage is a relatively new research field. GeM model is an applicable and sound tool for analyzing multimodal documents. The GeM Model takes language, layout, typography, and image into consideration in the analysis of the meaning-making processes of any documents. It treats the multimodal page as a multilayered semiotic artifact and stresses the distinctive role of each layer in the meaning-making procedure of the same multimodal page. The principal layers of the model are the base layer, the layout layer, the rhetorical layer, the navigational layer, and the generic layer, which can be identified in Table below. It is necessary to point out that the GeM model takes a more macroscopic view of layout. As such, it does not generally go down to the level of sentences or even characters, nor does it delve into the internal structure of the image.

\subsection{Research Methodology}

This is a contrastive case study that concentrates on Value Evaluation, Comparison, and classification on websites interfaces. The analytical object is the screenshots taken from the official website of the Confucius Institute and the "Russkiy Mir" Foundation to which people worldwide have free access. As evaluation indicators are highly subjective and easily influenced by objective conditions such as the network environment, quantitative transformation is needed when designing evaluation indicators. Therefore, based on the current website evaluation theory, the authors have designed a three-level evaluation index framework in three dimensions: information content, design and operation, and functional services, considering the actual situation with the development of the Confucius Institute's official website interface.

Meanwhile, hence it is of high importance to improve the ability to interpret multimodal documents concern with websites interface, this article will analyze the cases under the guidance of the GeM model. The point that needs to be clarified here is that the official website interfaces of the Confucius Institute and the "Russkiy Mir" Foundation has been revised during the article writing duration. Due to the GeM model takes a more macroscopic view of the layout, this research will pay attention to the base layer, layout layer, and navigation layer analysis.

\section{COMPARISON ANALYSIS OF WEBSITE SETTINGS}

\subsection{Case Study of Homepage}

The homepage serves as a gateway for the netizens to gain access to specific information from the website interface, a good layout can attract the user's attention while providing fast and convenient service.

\subsection{Confucius Institute Official Website Interface}

The Confucius Institute website includes the header, navigation area, news area and bottom navigation area. The Chinese homepage has a divider at the top, showing Beijing time on the left and a login screen on the right, which requires the user's name to be entered. The domain "Confucius Institute.com" shows its official context.

The header takes up a third of the entire homepage. At the top left of the header is the Confucius Institute logo with Chinese and English graphics. The search bar is at the top right and the default search mode is Chinese; when switching to English, French, Italian and Spanish, the language of the page switches as well. The main screen of the website scrolls through eight news items, mainly about recent events of the Confucius Institute attended by national leaders and important international forums hosted by the Confucius Institute. The first page of the main screen shows a slogan about China's solidarity in the fight against the virus.

The navigation area is horizontally arranged with 12 content lists, including: "About Us" "News Center" "Confucius Institutes," "Chinese Language Teachers " "Volunteers," "Teaching Resources," "Chinese Test," "New Chinese Learning Program "Scholarship" "Chinese Bridge" "Cultural Center" "Business Center. " Contains all Confucius Institute's core services. 
The news area, with the "Information Centre" section on the left, takes up 2/3 of the entire section. The Information Centre has four navigation sections based on content, namely "Confucius Institute News", "Announcements", "Media Focus" and "Subject Columns". Visitors can quickly access relevant information by clicking on the navigation categories. The information is arranged chronologically, and the content is easy to understand briefly. The right column of the news section contains graphic links to "Confucius Institutes (Classrooms) Worldwide", "Latest Video/Photo Album", "Me and My Confucius Institute" and "Notice of Chinese Language Teacher Volunteer Recruitment".

In summary, the news content in the left column tends to describe rational, objective news and reports, while the right column is more of a close-up, commentary on subjective feelings. The left and right columns achieve a combination of events and emotions, which can lead viewers to have more empathy for the heart.

At the bottom left of the news area, you can link to the landmark achievements and features of the Confucius Institute. It includes nine items: "Past Confucius Institute Conferences" "Latest National Teacher Recruitment Chapters" "Chinese Bridge" "Confucius Chinese Studies Program" "Volunteer Life" "Donated Books" "Confucius Institute Online" "Confucius Institute Magazine" "International Society for Teaching Chinese as a Foreign Language". Each project is marked with a distinctive icon and logo.

At the end of the home page is the bottom navigation area, the content directory is the same as the head navigation area but with an expanded table of contents, which is a reproduction of all the key information.

Confucius Institute official website has inserted a dynamic buoy on its front page, display ng the contents of the "Notice on the Extension of the 2020-2021 New Chinese Program's Deadline for The Ph.D. Program" to prompt critical incoming matters.

In addition to the above settings, there is a fixed buoy on the left-hand side of the home page which does not change position as the screen scrolls.

1) Link function: Clicking on the buoy can be linked to the logos to the "volunteer registration" "obtain donation book," "Chinese bridge," "scholarships," "Chinese teachers," "Chinese exam registration," "Confucius Institute/classroom application," meeting all the needs of the audience.

2) Connection function: After scanning the $Q R$ code with your mobile phone, we can follow the official account of the Confucius Institute in WeChat (the most popular social app in China), aiming to get the status of the Confucius Institute in the mobile client.

3) Sharing function: The official Confucius Institute website can be shared on many major Chinese social media platforms by clicking on the sprig in the image.

\subsubsection{Home Layout Analysis of "Russkiy Mir" Foundation's Website Interface}

The website's main home page is divided into six sections, the header, the navigation area, the news area, and the bottom area.

The header consists of two parts. At the top is a scrolling graphic link to the entry announcements for some of the most important international competitions recently organized by the Foundation. This includes a basic introduction to the "4th International Competition for Young Journalists", the "4th International Creative Competition 'Pushkin"' and the "4th Television and Radio Competition", as well as a review of the previous competitions. Beneath this is the "'Russkiy Mir"' Logo. The search bar is set next to the logo and searches are made in Russian mode by default, with search switches enabled for German, French, Italian, Spanish and English. Graphical links to "Russkiy Mir" Internet radio and TV channels, radio channels and news channels are provided next to the search bar. Navigation area

The navigation area lists nine content categories horizontally, including foundations, donations, news, publications, organization directories, education, books, and albums.

The news area consists of three sections. The first section is located under the navigation bar and is more visible. It mainly publishes national and international news relating to Russia, but also includes reports on the promotion of the Russian language and culture.

The second section is a scrolling bulletin board, featuring conference announcements with dates and countries as keywords, highlighting the conference theme and scrolling to guide the audience in navigating.

The left column of section 3 links to promoting Russskiy Mir's media, including video recordings, radio stations, photo albums, and publications. Meanwhile, "Russkiy Mir" and "Russia Central News" are arranged as thumbnails in the right-hand column. 
The bottom area is a recreation of the navigation bar, with the addition of the Foundation's contact details, a feedback bar and links to social media, including VK, YouTube, Facebook and more. There is also a hyperlink to the founding partners at the end.

\subsubsection{Summary}

Homepage features are the audience's overall perception and comprehensive feeling of web design. The GeM model provides a theoretical framework for empirical studies linked with layout design and computer techniques, aiming to scientifically analyze the page and documents and index the related multimodal corpus for querying.

As we can see from the screenshots of either Confucius institute or "Russkiy Mir", typical multimodal documents as text, photos, video, hyperlinks are all involved to construct the homepage as a meaningful tool. Firstly, both browsers of the cases can gain access to different versions by clicking the corresponding buttons. In a sentence or heading, the emphasized text portions are taken as embedded units. Within a sentence or phrase, the icons or similar pictorial signs, and the explicit references to other parts of a document are taken as embedded units. In a diagram or picture, the text pieces, the multimodally supported parts, and the graphical signs like arrows are taken as embedded units. In an interactive pop-up menu, the menu items are taken as embedded units. On web pages, the dynamically appearing labels that result in the clicking of the mouse are taken as embedded units. The utilization of embedding within base units preserves the essential unity of a unit while still making it available for the subsequent analysis of, well-specified portions of that unit. [Bateman, 2008] Secondly, both web-based elements that have been recognized so far are shown consist of a simple list of elements which are the basic components of the whole document. The current categorization is done from an empirical viewpoint. Their base units are labeled in terms of their functions aiming to facilitate the analyzing process of other layers, for example, the layout layer and the navigational layer.

According to screenshots of sections from the homepage of Confucius institute or "Russkiy Mir", the layout design of the two homepages shares similarities in some discernible alignments. Firstly, the white space framing performs a dividing role. It is evident that the homepage of the official website of Confucius institute adopts a left-right macro layout. Within its area model, the left column is divided into four parts and the right column is divided into seven parts. And its layout position is quite comprehensive as all the area is occupied. The homepage of the official website of the "Russkiy Mir" adopts a top-down macro layout. Within its area model, the parts inside are divided into smaller parts by utilizing either frames or a dividing line. Secondly, the deployment of the outer ring is similar. At the top and bottom of the two homepages, the layout layer accounts for approximately the same proportion in height for the entire spread.

Except for the above similarities, there also exist differences between the two homepages. Firstly, as can be seen from their respective area model, the overall layout of the homepage of the official website of "Russkiy Mir", is symmetric, while that of the homepage of the official website of the Confucius Institute is asymmetric. Secondly, the specific placement of content within the area model is different. The former spread has been fully covered while the latter has some evidently discernible blank area. It is assumed that the base layer and the layout layer are in place as described in this chapter in the following analysis of the rhetorical layer and navigational layer.

Compared with the "Russkiy Mir" homepage, there is a more clickable item in Confucius Institute, which indicates that it enjoys a higher degree of "invite-ability". The two homepages all utilize direct indicators like "more" to help the browsers in navigating through the web pages. As for both homepages, buttons are utilized by a similar proportion, and plain texts that function as hyperlinks account for quite a large proportion. There is a difference that needs to be pointed out here. Video does not appear on the homepage of Confucius Institute. While on the homepage of the "Russkiy Mir" the presentation of the video is signaled by an icon: This creates a better inviting effect for navigation.

\subsection{Multi-language setting and analysis}

\subsubsection{Multi-language Setting of Confucius Institute Official Website Interface}

The site is available in four languages. Chinese, English, French and Spanish. A comparison of the four language versions of the website mentioned above shows that the layout of the web pages is the same for the Chinese version and the other language versions. The overall content presented is relatively consistent, with only slight differences in the content in the news section. Taking the Chinese and English versions as an example, the content is as follows. 16 June 2020, the main screen of the Chinese version of the "Confucius Institute News" section contains 16 articles, 14 of which are about the Confucius Institute and its Chinese 
partner organizations cheering on the fight against the new pneumonia outbreak. The English version also has 16 articles on the main screen, 8 of which are about Chinese New Year celebrations in various countries and Confucius Institutes, 7 articles about other activities of Confucius Institutes and 1 article about Japanese Confucius Institutes supporting China in its fight against the new pneumonia epidemic. The articles in French and Spanish focused more on the daily activities of the Confucius Institutes in their respective language regions.

\subsubsection{Multi-language setting of "Russkiy Mir" Foundation's Website Interface}

The website of "Russkiy Mir" is available in Chinese, German, French, Italian, Spanish and English. By comparing the six language versions of the web pages mentioned above, it was found that the layout of the default Russian version of the homepage is not consistent with that of the other languages. Only the introduction of "Russkiy Mir" in the other language slots, except for the English version, and only news images in the remaining spaces. Inconsistent typography and asymmetrical information about the content. When clicking on the navigation bar "News", there is only a link to the news page in the Russian version and no link in the other languages.

\subsubsection{Summary}

The multilingual setting of the website is a necessary tactic to enhance the international image and influence and is also an important indicator of the level of website construction. The Confucius Institute's official website achieves a quick switch between Chinese, English, French and Spanish, compared to "Russkiy Mir" which translates into six languages and adds two more languages - German and Italian. However, when the Confucius Institute website switches languages, almost all the information content can be switched to the respective language; the "Russkiy Mir" website has enough information in Russian and English in view. After switching pages, the visuals in the other four languages only show the institution's description and pictures, with asymmetrical information. In contrast, the Confucius Institute's official website has a more logical multilingual set-up, with English, Chinese, French, and Spanish being the four most spoken languages worldwide. According to the Ethnologic website, these languages are spoken by over 3 billion people worldwide. Users of these languages access the website without access barriers and get enough information more quickly. Secondly, the Chinese version displays information content more symmetrically with other languages, allowing more trust to be built with non-Chinese speaking audiences. Combining these two points, the language setting of the Confucius Institute's official website is more conducive to promoting language and culture, building a cultural brand, and spreading China's cultural soft power.

\subsection{News Content Analysis}

\subsubsection{News Content in Confucius Institute Official Website}

The official website of the Confucius Institute is updated more frequently, but it is all in the news category. As an example, the news categories in Chinese and English from January 1, 2019 to December 25, 2019 are listed below. The news category includes the daily activities of the Confucius Institute, such as conferences, festivals, cultural performances, photography competitions, opening/closing ceremonies, training lectures, lecture forums and other Confucius Institute events. There were only 14 news articles, including sidebars on Confucius Institute activities, interviews with Confucius Institute directors and teachers, feature articles on Chinese language learners, and social commentary. Most of the news articles came from Confucius Institutes and Confucius Classrooms, while most of the other articles came from People's Daily, Guangming Daily, and www.people.com.cn.

\subsubsection{News Content of "Russkiy Mir" Website}

The "“Russkiy Mir" Foundation's website updates its news very frequently. From 25.12.2019 to 25.12.2020, the Russian version of the news reached more than 8580. All the News are categorized by source, by theme, by Country /Region. An advanced search by country/region is also available for news from "Russkiy Mir", but the classification is not sufficiently clear, and the results are incorrect.

\subsubsection{Summary}

The frequency, source and content of news updates can, to some extent, examine an organization's daily activities and promotional capabilities. In terms of timeliness, both websites are updated relatively frequently and on a relatively short cycle. But again, there are clear differences:

\section{1) Quantity}


According to statistics, from 1 December 2019 to 1 December 2020, 374 news items were published on the Confucius Institute website. More than 8,580 news items were published and republished by "Russkiy Mir".

\section{2) Content}

The news content on the Confucius Institute's official website is mainly focused on the major events and daily activities of the institution, of which $89.3 \%$ are narrative reports of news. At the same time, there are too few interviews, commentaries, features, newsletters and other in-depth reports and in-depth reflections, and there is a lack of introduction and promotion of traditional Chinese culture.

Russkiy Mir's news content coverage is more focused on shaping the country's image, reproducing news content related to all aspects of Russian culture, society, education, politics, economy, and tourism, in addition to the Institute's coverage.

3) Information publication

The website of "Russkiy Mir" also publishes the use of the fund and informs about projects for which the fund does not meet the requirements. By contrast, Confucius Institute Headquarters, as the world's top administrator of Confucius Institutes (Classrooms), does not publish those matters on its website.

\section{COMPARISON OF WEBSITE OPERATIONS AND FUNCTIONALITY}

\subsection{Website Operations Comparison}

The Website Operations can be analyzed from Website Traffic, Website PageRank, and Website Links.

\subsubsection{Website Traffic}

"Website traffic" is a measure of the users' number of a website, while the global ranking of website traffic can measure to some extent the popularity and influence of a website. The official website of the Confucius Institute was established in October 2005 and has a global ranking of 139,313. The website of Russkiy Mir was established in September 2007 and has a global ranking of 14,291. The data on website traffic is obtained from the "Alexa website traffic global ranking query".

a. Website Traffic of Confucius Institute 's website

The data on the percentage of visits by country/region shows that the most visited country on the official website of the Confucius Institute is the Kingdom of Macedonia, with $26 \%$ of visits and $42.1 \%$ of page views to its website. The second most visited country is Thailand, with $8.4 \%$ of visits and $8.7 \%$ of page views from Thailand.

\section{b. Traffic of "Russkiy Mir" Foundation's website}

Russia is the most visited country on the "Russkiy Mir" website. The rate of website visits was $57.9 \%$ and page views $57.1 \%$. The second ranked country is Belarus with $5.2 \%$ of website visits and $6.7 \%$ of page views. The third ranked country is Ukraine.

\subsubsection{Website PageRank}

PageRank (PR) is an algorithm used by Google Search to rank web pages in its search engine results. They range from 1 to 10 . The higher the PR rank, the more influential the position of the web page in the search rankings. When a website has a PR rating of 4 , it indicates that there are no problems with the site. A quick check shows that the Confucius Institute website has a PR of 9, while the website of "Russkiy Mir" has a PR of 4 .

\subsubsection{Website Links}

Website links are divided into internal links and external links. 1) "Internal links". Internal links are links to pages under the domain name of the website. Investigate whether there are dead pages that cannot be displayed and whether there are sections that have not yet been created. The internal links on the Confucius Institute's official website are valid. However, there are no links to "more" in the "Teachers" section and the "Examinations" section. The internal links to the Russian and English versions of the "Russkiy Mir" website are valid. However, there are dead links and uncreated links.

\section{2) External Links}

An 'external link' is a link to a page or other element in another website domain. Examine the number and type of hyperlinks. The official Confucius Institute website has nine sections related to international Chinese 
language teaching and the Confucius Institute. The website of "Russkiy Mir" has six hyperlinks to the websites of the "Ministry of Science and Education of Russia", the "Ministry of Foreign Affairs", the "Association of Teachers of Russian Language and Literature", the "Association of Teachers of Russian Language and Literature", and two of the most prestigious universities.

\subsection{Website Function Comparison}

\subsubsection{Navigation Function}

The navigation of the websites of both organizations can be linked to the content. However, the Russkiy Mir website must select the language on the homepage. Other internally linked pages cannot switch languages; the organization's logo must be clicked on to return to the home page. The Confucius Institute website does not have such problems.

\subsubsection{Retrieval Function}

The websites of both institutions offer keyword searches. News from the Confucius Institute can be searched by keywords and news from "Russkiy Mir" can be searched by country or regional classification as well as by news topic/theme (but exact results cannot be obtained by regional classification).

\subsubsection{Online Function}

The Confucius Institute offers online applications for places in the HSK test center, the New Chinese Language Learning Program, the Confucius Institute scholarship application, and the online education function (Online Confucius Institute). "Russkiy Mir" can provide online applications for donations.

\subsection{Comparison}

The functional development of the websites of these two institutions has been completed. However, they still need a lot of manpower and material resources to keep the websites running. Some unfinished modules need to be built faster, and some completed modules need to be further improved and continuously updated. In the new era, both the Confucius Institute and the Russian Centre are responsible for the dissemination of national language and culture, and a good bilateral relationship determines the great role of language and culture in the process of national cultural interaction. Therefore, both should learn from each other's successes and take advantage of the opportunities for mutual development to contribute to the international spread of languages.

\section{SUMMARY AND SUGGESTIONS}

After comparing the websites' basic settings, the author finds that Confucius Institute Headquarters' website is relatively better in construction, operation, and maintenance investment parts, but weak in characteristic and cultural function parts." Meanwhile, the "Russkiy Mir" Foundation's website is unique in content construction, but the operability and functionality need to strengthen. In conclusion, perfecting the website's construction is an effective complement to both agencies' product cultural capital.

Compared with Confucius Institute Headquarters' website, Russkiy Mir's website is more attractive and helps the audience understand modern Russia's society and culture, which can play its function of cultural communication. However, due to the defects of the setting, it is difficult for the public whose native language is not Russian to navigate, which to a certain extent hinders the dissemination and promotion of the Russian language and culture to the outside world. It is worthwhile to learn that Russkiy Mir publishes the monitoring of various projects through its website, which plays a particular role in public supervision and enhances the public's trust in the Foundation.

In Joseph Nye's discourse, the concept of the subject of national soft power, which is placed in the arena of the Internet, is implemented at a concrete level and is reflected in the international discourse of language and cultural promotion agencies on the Internet. In the construction of soft power, the Internet shows its function as a medium of expression. In the construction of the platform, it is important to take full cognisance of the cultural differences, complexity and initiative of internet users, to make it a basic principle of external communication to ensure the authenticity and validity of the discourse, to actively expand the scale of the discourse platform system, to diversify the forms of dialogue and communication, to accelerate the spread of the discourse, to build an authoritative external discourse platform and to improve cultural soft power.

Language is an essential component of soft power, and language and cultural communication institutions have demonstrated an irreplaceable and vital role as an effective platform for building national soft power. Confucius Institute Headquarters and Russkiy Mir are the official language and culture promoting agencies 
of China and Russia, shouldering the responsibility of spreading Chinese / Russian language and culture and promoting the shared prosperity of the world's multi-cultures. Confucius Institutes and the "Russkiy Mir" Foundation are becoming culture- exporting symbols tasked with safeguarding national interests, shaping the national image, and strengthening friendly relations between countries, accumulating specific individual cultural capital in continuous development.

In this era of global networking, it is imperative to strengthen Internet communication's strategic planning and practice by using the network platform effectively. From the analysis above, it is not difficult to find out that there are still some problems with the websites of Confucius Institute Headquarters and Russkiy Mir:

Confucius Institute Headquarters' website construction is relatively sound, the setting is reasonable, the operation and maintenance investment is relatively substantial, but the contents displayed are limited to the internationalization, ignored the actual needs of website users, which lack of ability to lead users to understand the current situation of Chinese society and to understand of Chinese culture.

Russkiy Mir's website is more attentive in its content construction, focusing on the display of Russian society and Russian culture. However, its website has more operation and function problems. The process's operation is more troublesome and is not friendly enough for non-Russian and English users.

Because of the problems that arise on the websites of the two agencies, the author puts forward the following suggestions:

\subsection{Suggestions for Confucius Institute Headquarters' website}

\subsubsection{Strengthen the External Link Function.}

To establish links to Chinese state media and websites with Chinese characteristics, such as the Ministry of Foreign Affairs of China, the Belt and Road, China Daily, Peking University, and Tsinghua University, enrich user needs.

\subsubsection{Strengthen Content Construction}

To enrich the website's content reasonably, reduce the news-type reports, meet the user's demands on information about Chinese society, Chinese culture, and create a positive cultural atmosphere. Explore the deep-seated value concepts, value requirements, and aspirations of the target users of the website.

\subsubsection{Improve Language Settings}

According to the "Belt and Road" construction's practical needs, to increase Russian, Thai, and other languages settings, to reduce reading barriers, deepen along with the people's understanding of the "Belt and Road."

\subsubsection{Strengthen the Functional Construction of the Website}

To identify website targeting and users, according to different user groups targeted to provide information. For example, distinguish users between relevant institutions, students, and general visitors.

\subsubsection{Strengthen Brand Awareness.}

To learn from the brand-promotion experiences of famous language and culture promotion institutions such as "Goethe College," "Cervantes College," and "French Alliance" to utilize the network platform better and promote the construction of connotation.

\subsection{Suggestions for Russkiy Mir Foundation's website}

\subsubsection{Strengthen the Supervision and Maintenance of the Website.}

To investigate the construction of the website, timely collect statistics on the construction of the site of the existing problems to rectify.

\subsubsection{Strengthen the Level of Multi-Language Construction of the Website.}

To reduce information asymmetry caused by switching languages. Improve the Russkiy Mir website construction team for the website's sustainable development to provide technology, language, business, and other aspects of support and protection.

\subsubsection{Strengthen the Functional Construction of the Website}


To identify website targeting and users, according to different user groups targeted to provide information. For example, distinguish users between relevant institutions, students, and general visitors.

\subsubsection{Strengthen Brand Awareness}

To learn from the experience of brand communication of language and culture promotion institutions such as "Goethe College," "Cervantes College," and "French Alliance" to utilize the network platform better to promote the construction of connotation.

\section{REFERENCE LIST}

Askehave, I., \& Nielsen, A. E. (2005). Digital genres: a challenge to traditional genre theory. Information technology \& people.

Bateman, J. A. (2017). Multimodality and genre. In Information Design P. 237-258. Routledge.

Bourdieu, Pierre. (1977). Outline of A Theory of Practice. Cambridge University Press. P. 188.

Bhatia, V. K. (2004). Worlds of written discourse: A genre-based view. A\&C Black.

Chang Yishuo, Chen Mengjin, Cui Mingyue. (2018). A guide to cross-cultural communication from a comparative study of Confucius Institutes and Russian language centers. Communication Power Research. Vol. 000(007): P.24-25.

Cheng, W., \& Suen, A. O. (2014). Multimodal analysis of hotel homepages: A comparison of hotel websites across different star categories. The Asian ESP Journal, Vol. 10(1), P. 5-33.

Chen, Haiping. (2012). Content analysis and comparison of Chinese and American university websites. Education Science Digest, [陈海平. (2012). 中美高校网站的内容分析与比较. 教育科学文摘]. Vol.3, 2829. (In Chinese).

Decree of the Russian Federation President on the establishment of the "Russkiy Mir foundation" signed by Vladimir Putin. Available at: https://org.ru/2007/6/23/fond-dok.html

Dong Lu. (2011). Confucius Institute and Goethe Institute: Cross-Cultural Communication under Different Concepts. Journal of the Institute of International Relations, [董璐. (2011). 孔子学院与歌德学院:不同理 念下的跨文化传播. 国际关系学院学报].Vol. 04. P. 101-107. (in Chinese)

Gibbon, D., Mertins, I., \& Moore, R. K. (2000). Representation and annotation of dialogue. In Handbook of multimodal and spoken dialogue systems P. 1-101). Springer, Boston, MA.

Krasina, O.V. (2011). "Myagkaya sila" kak teoreticheskaya konstrukciya i vlastnaya tekhnologiya sovremennoj mirovoj politiki. ["Soft power" as a theoretical construction and power technology of modern world politics]. Izdatel'stvo Sovremennogo gumanitarnogo universiteta (in Russian).

Kress, G., \& Van Leeuwen, T. (1996). Reading images: The grammar of visual design. Routledge.

Kosachev, K. (2012). The specifics of Russian soft power. Russia in Global Affairs, 7.

ledema, R. (2003). Discourses of post-bureaucratic organization Vol. 5. John Benjamins Publishing.

Leonova, O.G. (2013). Myagkaya sila - resurs vneshnej politiki gosudarstva [Soft power - a resource of foreign policy of the state. Observer] Obozrevatel'. Vol. 4. P. 27-40. (in Russian)

Li, Qinzheng. (2016). A comparative study of Confucius Institute and Russian Language Center (Master's thesis, Liaoning Normal University). [李琴筝. (2016). 孔子学院与俄语中心的对比研究 (硕士学位论文,辽 宁师范大学]. (In Chinese).

Li, Baogui. (2017). Confucius Institute and Russian Language Center in Cultural Interaction: A Comparative Study on the Philosophy of School Operation. Journal of Northwest Normal University (Social Science Edition). [李宝贵. (2017). 文化互动中的孔子学院与俄语中心:办学理念的比较研究. 西北师大学报(社会 科学版].Vol.1.P.121-127. (in Chinese). 
Liu Liping, Jiang Xinxin. (2011). The Path to Sustainable Development of Confucius Institutes from Goethein-law. Contemporary Education and Culture. [刘丽萍, 姜欣欣. (2011). 从歌德学院看孔子学院的可持续 发展之路. 当代教育与文化 ]. Vol. 3. P. 83-87. (In Chinese).

Liu Huan, \& Lu Beiyong. (2012). A comparison and reflection of Chinese and American university portals. China Education Informatization, [刘欢, \& 卢蓓蓉. (2012). 中美高校门户网站的比较与思考. 中国教育信 息化]. Vol 3, P. 6-8. (In Chinese).

Men Honghua. (2007). China's soft power assessment report. International Observation.

Swartz, D. (1977). Culture and Power. Chicago University Press. P. 188.

The "Russkiy Mir" Found's official websites. URL: https://www.russkiymir.ru (The data of this article was collected on 16.2.2020)

The Confucius institute's official websites. URL: https://www.cief.org.cn/kzxy (The data of this article was collected on 16.2.2020)

Xu Jialu. (2017). The Future and Mission of Chinese Culture. China Bookstore. [许嘉璐. (2017). 中华文化的 前途和使命. 中华书局]. P. 135. (in Chines)

"Xi Jinping (2014). Attends Central Foreign Affairs Work Conference and delivers important speech," Xinhua, November 29,

Zhang, Delu. (2009). Multimodal Discourse Theory and Its Application to Foreign Language Teaching with Modern Media Technology [J]. Foreign Language Education,[张德禄.(2009). 多模态话语理论与媒体技 术在外语教学中的应用. 外语教学]Vol 4. P. 15-20. (in Chinese). 